\title{
INFLUENCE OF EXECUTION TOLERANCES FOR FRICTION CONNECTIONS IN CIRCULAR AND POLYGONAL TOWERS FOR WIND CONVERTERS
}

\author{
Christine Heistermann ${ }^{1}$, Marko Pavlović ${ }^{1,4, *}$, Milan Veljković ${ }^{1,4}$, \\ Daniel Pak ${ }^{2,5}$, Markus Feldmann ${ }^{2}$,Carlos Rebelo ${ }^{3}$ and Luis Simões da Silva ${ }^{3}$ \\ ${ }^{1}$ Steel Structures, Luleå University of Technology, 97187 Luleå, Sweden \\ ${ }^{2}$ Institute for Steel Construction, RWTH Aachen University, Mies-van-der-Rohe-Straße 1, 52074 Aachen, Germany \\ ${ }^{3}$ ISISE; Department of Civil Engineering, University of Coimbra, Rua Luis Reis Santos, Pólo 2, \\ 3030-788 Coimbra, Portugal \\ ${ }^{4}$ Delft University of Technology, Faculty of Civil Engineering and Geosciences, Stevinweg 1, \\ 2600 GA Delft, The Netherlands \\ ${ }^{5}$ Universität Siegen, Paul-Bonatz-Str. 9-11, 57076 Siegen, Germany \\ *(Corresponding author: E-mail: m.pavlovic@tudelft.nl)
}

Received: 9 June 2016; Revised: 15 August 2016; Accepted: 29 October 2016

\begin{abstract}
Friction connections with long open slotted holes have been proven to be a competitive alternative to the conventional flange connections in steel tubular towers for wind energy converters. As full-scale tests are not available, results of Finite Element Analysis (FEA) of the real-scale tower geometry are used in this paper to investigate the influence of tower cross section shape, execution tolerance (gap between the shells) and length of the connection on the bending resistance. Buckling behaviour of the shell in the vicinity of the friction connection in circular and polygonal towers is compared. The friction connection is thoroughly examined and recommendations for execution tolerances are given. The influence of two types of the execution tolerances on the connection strength is considered: inward bended "fingers", leading to inclined gaps, and a parallel gap created by different tower diameters.
\end{abstract}

Keywords: steel tubular tower, wind energy converter, friction connection, long open slotted hole, circular cross section, polygonal cross section, execution tolerance, FEA

DOI: $10.18057 /$ IJASC.2017.13.4.2

\section{INTRODUCTION}

Steel tubular towers are the most common support for wind energy converts. They reach heights up to $100 \mathrm{~m}$, which is limited by the size of the shell diameter of up to $4.5 \mathrm{~m}$. Transportation issues impose the maximum value for shell diameter. In recently finished RFCS (Research Fund for Coal Steel) projects, "High-strength tower in steel for wind turbines (HISTWIN)" Veljkovic et al. [1] and "High steel tubular towers for wind turbines (HISTWIN2)" Veljkovic et al. [2], the use of technical innovations to increase competiveness of steel tubular towers was one of the main topics. One important innovation is the use of so-called "friction connections with long open slotted holes" for in-situ execution, see Figure 1. This connection has been shown as a competitive alternative to the conventional ring flange connection of the steel tubular tower for a hub-height up to $100 \mathrm{~m}$. The material cost for the connection, which takes into account shell material and bolts, is about $80 \%$ lower for the adequate resistance, according to Veljkovic et al. [1].

In the friction connection, the outer shell (upper segment) is equipped with fitted bolts, close tolerance holes, on the side of the bolt head, while the inner shell (lower segment) has open slotted holes with the width of the hole equal to the normal clearance hole diameter, see Figure 1. Feasibility tests on tower segments, $2 \mathrm{~m}$ in diameter, carried out within HISTWIN and HISTWIN2 project, Veljkovic et al. [1] and [2], proved that the bolts can be pre-installed in the 
upper segment and easily slid on top of the lower segment with an execution tolerance providing a $10 \mathrm{~mm}$ initial gap between the shells, see Figure 2. Diameters of towers with common height of 80 - $100 \mathrm{~m}$ are large e.g. up to $4 \mathrm{~m}$ and thicknesses of shells can go up to $60 \mathrm{~mm}$, depending on site condition, wind turbine class, and steel grade used. As a rule of thumb, the initial shell thickness which can be assumed for the pre-designed considerations is about $1 \%$ of the shell diameter. Therefore, relatively larger execution tolerances are needed for the execution of real-scale tower.

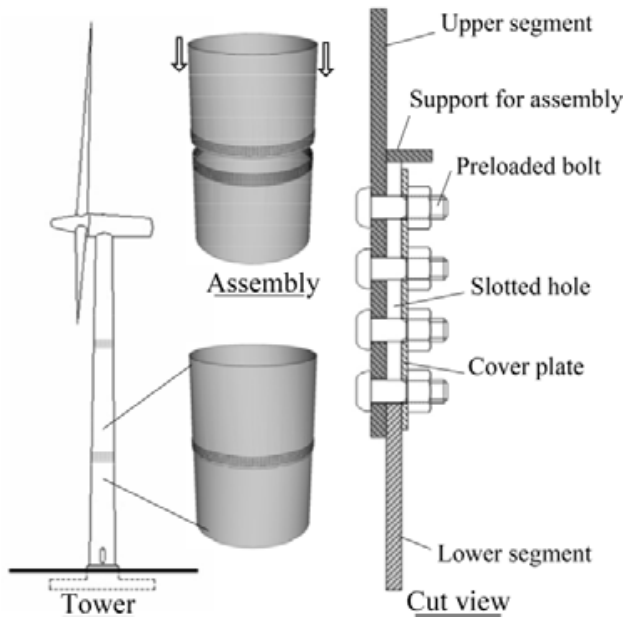

Figure 1. The Friction Connection in Tower for Wind Converters, Veljkovic et al. [1]

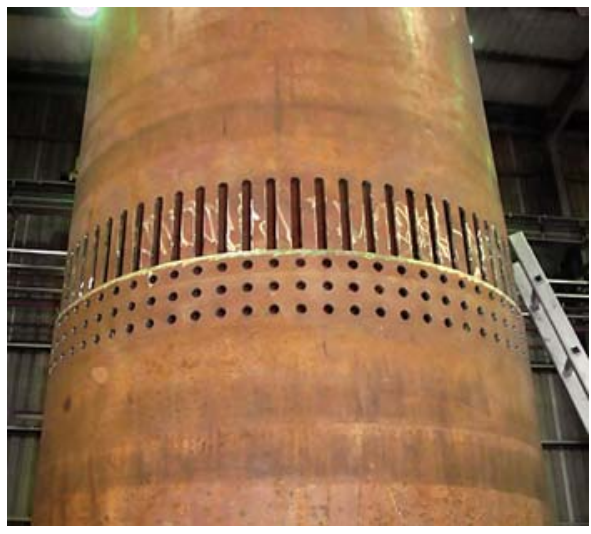

a) HISTWIN Project [1]

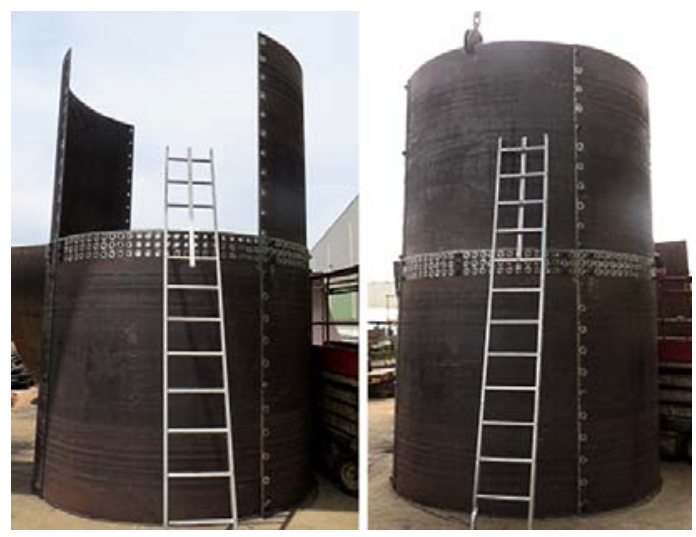

b) HISTWIN2 Project [2]

Figure 2. Feasibility Tests Performed in Previous Projects

Down-scale experiments on tower segments with friction connection have been conducted within the scope of HISTWIN project, Veljkovic et al. [1], but neither tests or field measurements are available with real dimensions of a tower. It is worth noting that photos shown in Figure 2 show feasibility testing which is performed so the upper segment of the tower is placed at the ground. This choice is made by workers in the workshop, just for their convenience, this decision has no consequences on any conclusion relevant for the research project.

It is unrealistic to expect that experiments up to failure of such large specimens will ever be realised, especially having in mind the possibilities of advanced FEA as demonstrated in this paper. Thorough examination of slip and buckling behaviour of the friction connection in a tower with circular cross section is given by Pavlović et al., [3] and [4], respectively. The time dependent loss of the bolt preloading force in the friction connection has been considered in Heistermann et al. [5]. Polygonal tower shapes have been studied by Garzon [6] and Reinke [7], providing numerical and 
experimental evidences on the buckling behaviour of tower segments with polygonal cross section, respectively. The friction connection in polygonal towers has been reported in the HISTWIN2 project, Veljkovic et al. [2].

The aim of the research presented here, is to comprehensively examine the behaviour of the friction connection in circular and polygonal towers including the influence of local buckling of the shell in the vicinity of the connection and the influence of execution tolerances. Quasi-static analysis is made with ABAQUS FE software package, see [8], using the explicit dynamic solver coupled with damage material models. The assumed tower segment has a diameter of the shell of $D=3374 \mathrm{~mm}$, thickness $t=24 \mathrm{~mm}$, steel grade S460 and high-strength bolts M48, grade 10.9, are used for the connection. Details of the connection are shown in Figure 3. Dimensions and values of design loads $\left(M_{\mathrm{Ed}}=45.8 \mathrm{MNm}\right)$ at the analysed connection cross section are based on the design of a "real" tower with the common ring flange connection. Local buckling of the shell in the vicinity of the friction connection is analysed considering design shell imperfections in the circular and the polygonal tower.

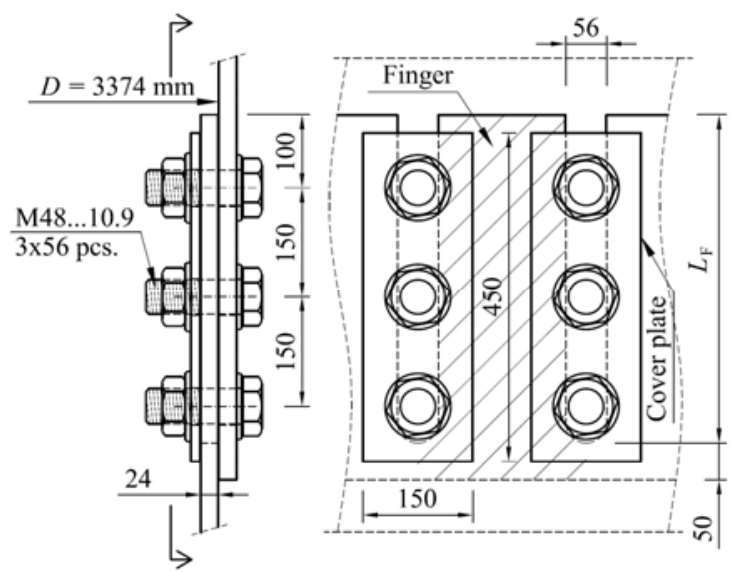

Figure 3. Layout of the Friction Connection in a Real-scale Tower Considered in the Study

A possible solution to ensure the execution tolerance is the provision of a gap between the outer and the inner shell obtained by different diameters. The second alternative is to pre-bend "fingers" of the inner shell which has the same outer diameter as the inner diameter of the outer shell. These alternatives and the size of the execution tolerance are examined in this study.

In order to validate the FE modelling and the computational procedure, the experimental results of the down-scale 4-point bending tests conducted by Pak and Naumes [9] on $8 \mathrm{~mm}$ thick shells with a diameter of $1 \mathrm{~m}$ and the total span of about $7 \mathrm{~m}$ are used.

\section{FINITE ELEMENT ANALYSIS}

Two FE models of the friction connection shown in Figure 3 are created: a connection in a tower with circular cross section (FCC) and a connection in a tower with polygonal cross section (FCP), as shown in Figure 4. The friction connection is designed with three rows of 56 bolts each, and cover plates to have sufficient slip resistance so that the buckling resistance of the connection becomes the dominant failure mode.

The polygonal tower shape has 14 edges (folds). The governing criterion for such division is to be at the boundary to local buckling of a flat part of the cross section, a segment between the folds, i.e. keeping the slenderness of the flat part close to the lower limit for the cross section of class 4 according to EN 1993-1-1 [10], see Eq. 1 and Eq. 2. 
$c_{\text {flat }} / t \leq 42 \varepsilon \Rightarrow c_{\text {flat }} \leq 42 \cdot 0.71 \cdot 24=716 \mathrm{~mm}$

$n_{\text {edge }} \geq \frac{\pi D}{c_{\text {flat }}}=14.8$

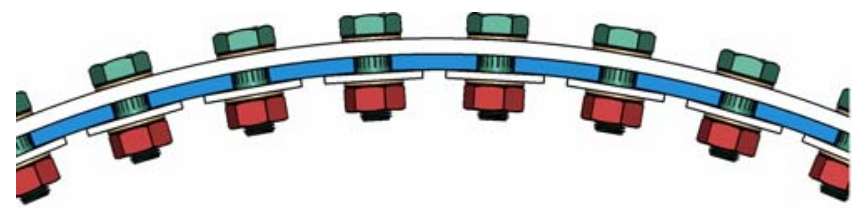

a) Circular Tower Shape (FCC)

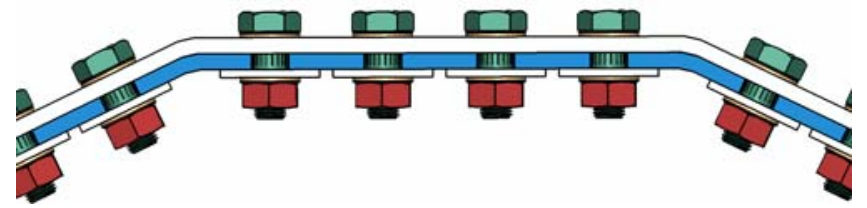

b) Polygonal Tower Shape (FCP)

Figure 4. Different Tower Shapes Considered in the Case of Friction Connection

\subsection{Geometry, Boundary Conditions and Mesh}

The FEA model geometry and boundary conditions of one half of the tower segment including the most possible refinement of the connection details shown in Figure 5 and Figure 6. Symmetry boundary conditions for bending are used to reduce the computation time. The tower segment is $3 \mathrm{~m}$ long on each side of the connection. This size of the model is chosen for proper modelling of the connection, local buckling of the shell and to allow redistribution of meridional stresses. Preliminary FEA was used to justify dimensions and costs of the feasibility tests which has been confirmed by the detailed analysis shown here. Cross section surfaces of the shells are fully kinematically constrained to the reference points.

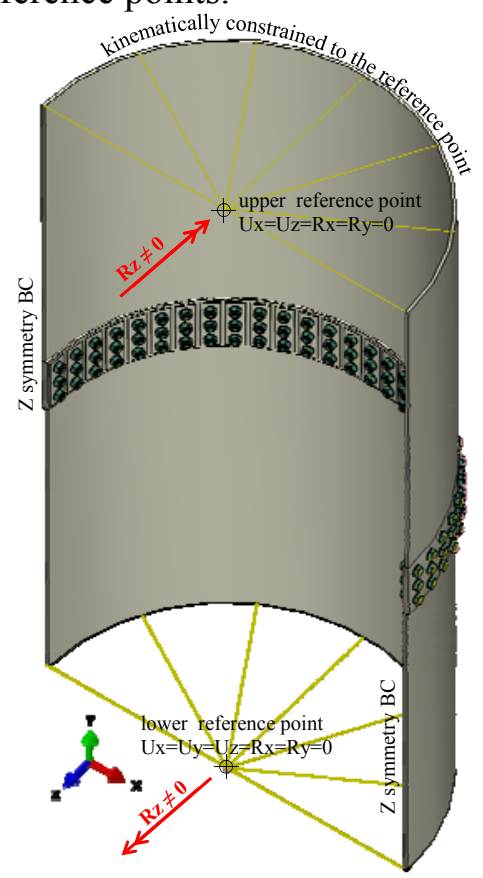

Figure 5. Geometry of the Model and Boundary Conditions 
Bolts and nuts are modelled with the real thread geometry, see Figure 6 and preloading of the bolts is applied by the turn-of-nut method, see Figure 7. Tetrahedron solid elements (C3D4) are used to form the bolt mesh. Global element size of the bolt is $11 \mathrm{~mm}$, while in the threaded zone the element size is reduced to $5 \mathrm{~mm}$. Eight node hexahedron solid elements with reduced integration (C3D8R) are used for the shell with element size of $20 \mathrm{~mm}$. The shells and the cover plates are meshed with four elements through the thickness to properly take into account the bending stiffness.

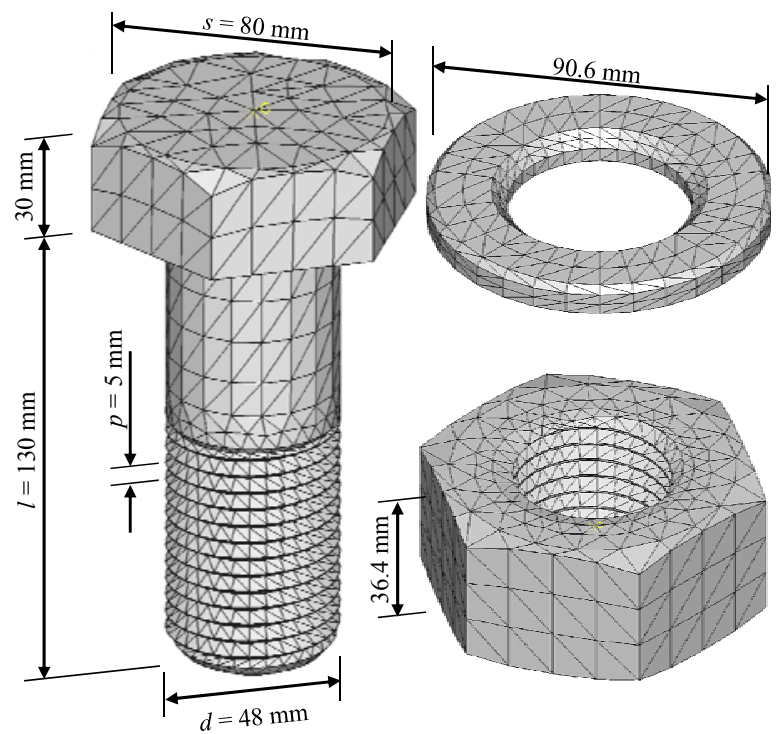

Figure 6. Geometry and Mesh of the Bolt, Washer and Nut

General contact interaction procedure is used in ABAQUS/Explicit with "hard" formulation of normal behaviour and "penalty" friction formulation of tangential behaviour, see [8]. The friction coefficient of 0.14 is set for bolts and nuts threads surface pairs according to recommendation given in ECCS Publication No. 38 [11]. For all other surface pairs in the model a nominal Class A friction surface is assumed with the slip factor $\mu=0.5$ according to EN 1993-1-8 [12] in the parametric study performed here. The sophisticated modelling of bolts is necessary to have appropriate stiffness of the bolt and connection, however the full benefits of its complex analysis are emphasised at the ultimate limit state of the connection, see references [2], [3], [4], and Pavlovic et al. [13].

\subsection{Loading and Computational Procedure}

Two computation steps are analysed for each model: preloading of the bolts and bending to the failure. Preloading of the bolts is applied by the turn-of-nut method. Hexagon edges of nuts are kinematically coupled to the reference points in the centre line of each nut, as it is shown in Figure 7a. Those reference points are turned by applying changes in boundary conditions, i.e. by rotating around the axis parallel to the shank of each bolt. The targeted preloading force of $960 \mathrm{kN}$ is calculated according to EN 1993-1-8 [12] for M48 bolts, grade 10.9. Rotations of the nuts are calibrated in each case to achieve this targeted preloading force. Values of the bolt preloading forces are obtained by summation of node forces in the cross section of the bolt, see. In Figure $7 b$, the stress in the bolt, shells and cover plate in the friction connection are shown for the final stage of preloading. 
Table 1. Rotations of the Nuts and Resulting Preloading Forces

\begin{tabular}{ccccc}
\hline Case & $\begin{array}{c}\text { Grip } \\
\text { length } \\
(\mathrm{mm})\end{array}$ & $\begin{array}{c}\text { Gap } \\
(\mathrm{mm})\end{array}$ & $\begin{array}{c}\text { Nut } \\
\text { rotation } \\
\text { (rad) }\end{array}$ & $\begin{array}{c}\text { Obtained } \\
\text { preloading } \\
\text { force }(\mathrm{kN})\end{array}$ \\
\hline FCC & 60 & 0 & 3.83 & 960 \\
& 60 & 10 & 16.40 & 1024 \\
\hline FCP & 60 & 20 & 28.95 & 892 \\
\hline 60 & 30 & 41.52 & 893 \\
\hline & 60 & 0 & 1.00 & 905 \\
& 60 & 10 & 13.60 & 964 \\
\hline
\end{tabular}

The bending moment is applied "displacement controlled" by imposing rotations of upper and lower reference point as shown in Figure 5.

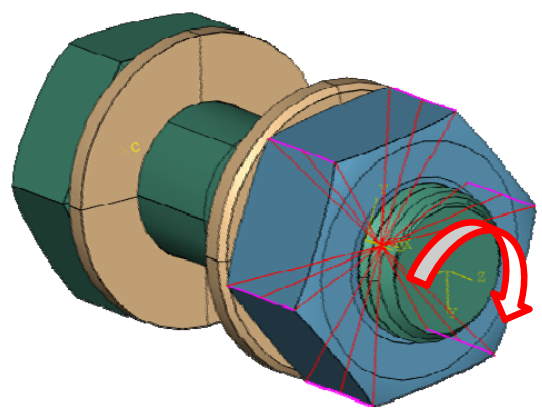

a) The Turn-of-nut Method

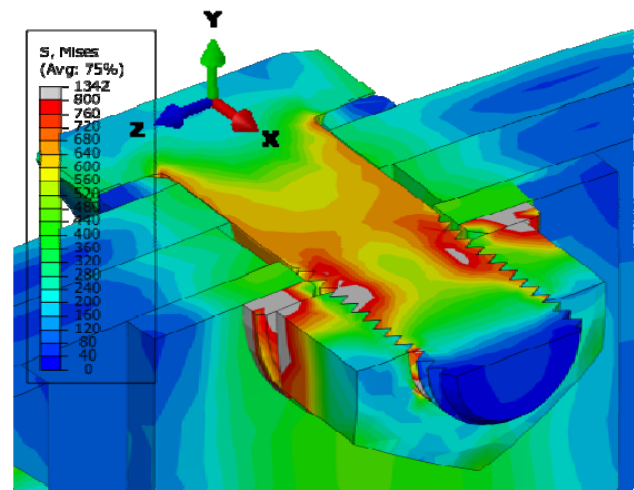

b) Stresses in the Bolt, Shells and Cover Plate

Figure 7. Preloading of the Bolts

Explicit dynamic solver of ABAQUS is known to be robust for this kind of analysis, where complex contact interactions coupled with large deformations and nonlinear behaviour are present, see [8]. It does not have usual convergence problems such as the implicit static solver. However, the computation may be quite long, if the real dynamic response of the model is required. Loading is supposed to be quasi-static. In this model the dynamic solver is used to efficiently solve the quasi-static problem. Calculation time is shortened by using variable non-uniform mass scaling technique with the target time increment set to $\Delta t=5.0 \times 10^{-5} \mathrm{~s}$. Artificial durations are adopted for two computation steps: $7 \mathrm{~s}$ and $10 \mathrm{~s}$, for preloading of the bolts and loading up to failure, respectively. Trial computations are made in order to select the appropriate target time increment and to avoid unwanted inertia forces in quasi-static FEA.

\subsection{Material Models}

Measured data of material properties are used for the verification FEA, while nominal material values are used for the bolts and the shells in the real-scale FEA, as given in Table 2. Isotropic hardening plasticity with modulus of elasticity of $E_{0}=210 \mathrm{GPa}$, and Poisson's ratio of $v=0.3$ is used for all materials. Bolts, washers and nuts are set to nominal values of stress at the yield point $f_{\mathrm{y}}=900 \mathrm{MPa}$ and ultimate strength $f_{\mathrm{u}}=1000 \mathrm{MPa}$, with the ultimate elongation $A=10 \%$ according to ISO 898-1 [14] for bolt material grade 10.9, see Figure 8. A parabolic shape of the nominal stress-strain curve is assumed to enable the definition of the damaged plasticity material model of bolts. 
Table 2. Material Properties used in FEA

\begin{tabular}{|c|c|c|c|c|c|}
\hline Material & Steel grade & $\begin{array}{l}\text { Thickness } \\
t(\mathrm{~mm})\end{array}$ & $\begin{array}{l}\text { Yield } \\
\text { strength } \\
f_{\mathrm{y}}(\mathrm{MPa})\end{array}$ & $\begin{array}{l}\text { Ultimate } \\
\text { strength } \\
f_{\mathrm{u}}(\mathrm{MPa})\end{array}$ & $\begin{array}{l}\text { Ultimate } \\
\text { elongation } \\
A(\%)\end{array}$ \\
\hline $\begin{array}{l}\text { Down-scale } \\
\text { verification FEA }\end{array}$ & $\mathrm{S} 355 \mathrm{~J} 2+\mathrm{N}$ & 8 & 415 & 534 & - \\
\hline High-strength bolts & 10.9 & - & 900 & 1000 & 10 \\
\hline $\begin{array}{l}\text { Shells in real-scale } \\
\text { FEA }\end{array}$ & S460 & 24 & 460 & 550 & - \\
\hline
\end{tabular}

A ductile damage model is used to model the failure of the bolts. The hardening part of the material behaviour is defined by the plasticity curve while the softening part and the failure are governed by the damage initiation criterion and the damage evolution law. Parameters of ductile damage initiation criterion and damage evolution law are derived analysing undamaged and damaged material response in a standard (round bar) tensile test, as described by Pavlović et al. [145]. The standard (round bar) tensile test model is created and material parameters are calibrated by comparing the nominal stress-strain curve to the FE results, as shown in Figure 8. Details of the calibration procedure for the material models of the bolt are given by Pavlovic et al. 3].

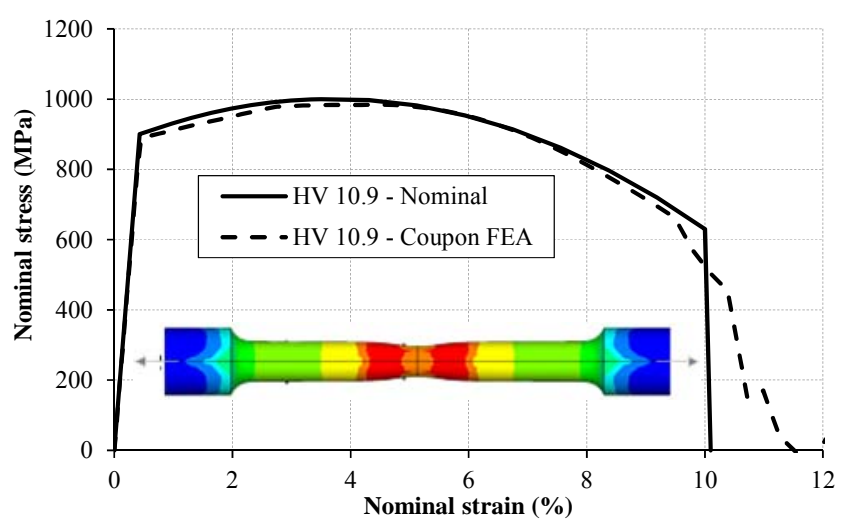

Figure 8. Comparison of Nominal and FEA Tensile Tests Results for Bolts

The same element type (C3D4) and corresponding size $(5.0 \mathrm{~mm})$ used in the validation of the material model is used for bolts in the FE models of real-scale connections.

\section{$2.4 \quad$ Verification of FEA by Down-scale Experiments}

In order to prove the validity of the FEA study presented here, verification is made with respect to the experimental data of down-scaled tests of tower segments. The layout of the 4-point bending experiments conducted at RWTH Aachen University, see Veljkovic et al. [1] and Pak and Naumes [9], is shown in Figure 9a. The ring flange connection and the friction connection using 32 M20 bolts and 24x3 M20 bolts, respectively, were tested with shell diameter $1 \mathrm{~m}$ and thickness $8 \mathrm{~mm}$ over a $7 \mathrm{~m}$ span. The same computational procedure, which is used for the verification of FEA, is used for the real dimensions of the tower segment in this study. 


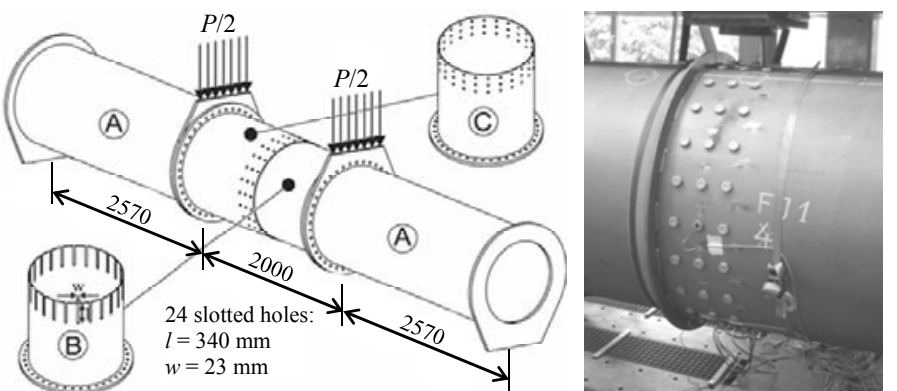

a) test set-up

b) detail of the connection

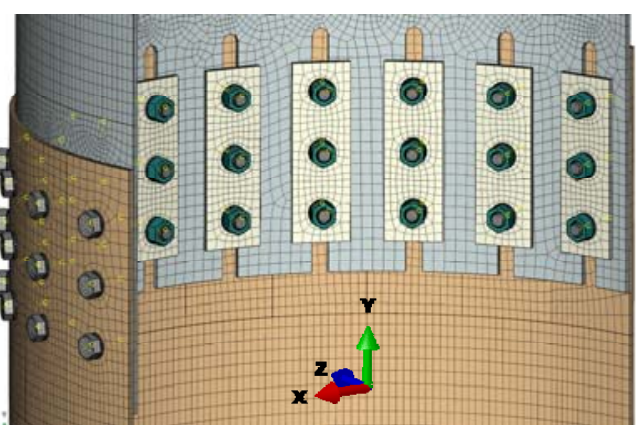

c) FE model

Figure 9. Experiments and FE Model of the Down-scaled Tower Segment

Comparisons of the experimental and FE results for the friction connection are shown in Figure 10. More details about verification of FEA are given by Pavlovic et al. ]. Very good agreement is achieved for both failure modes buckling of the shell in case of the ring flange connection and slip failure for the specimen where the friction connection is used. This has justified use of the same FE model for analysis of the full scale connections.

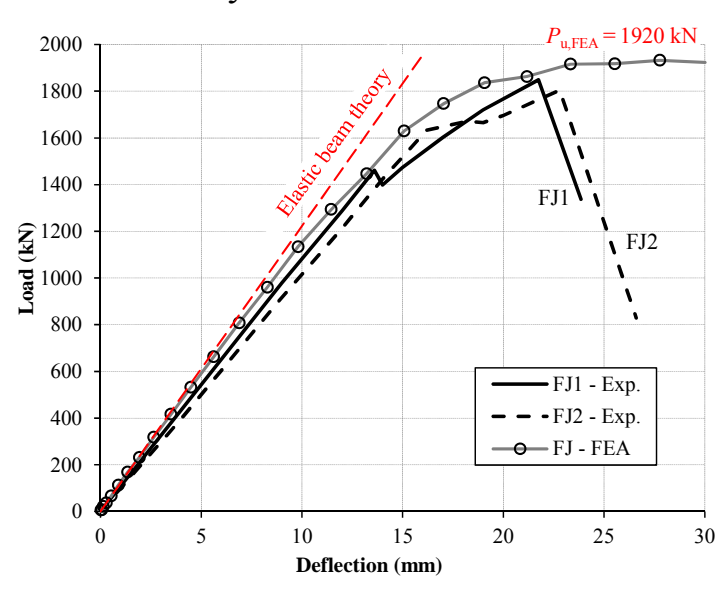

a) load-deflection curves

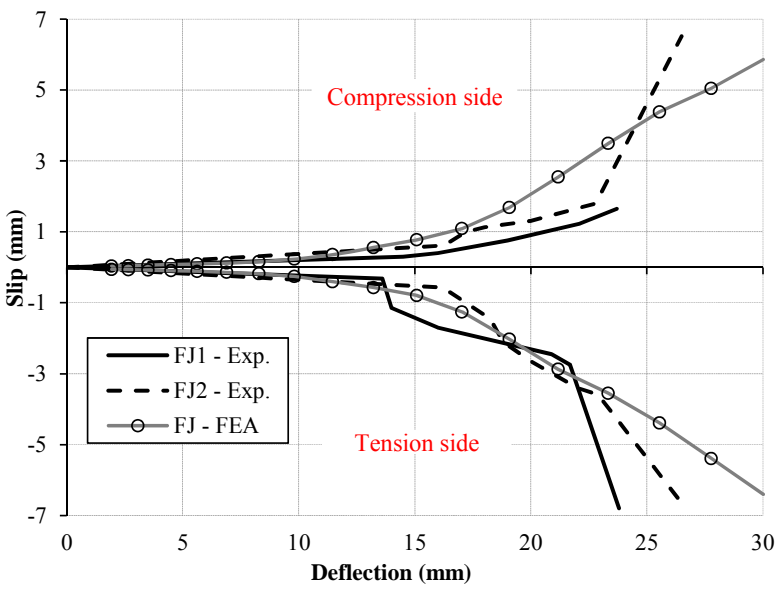

b) slip at the end of finger

Figure 10. Results of the Verification FEA vs. Experiments on the Friction Connection

\subsection{Shell imperfections}

Friction connections in circular and polygonal tower shapes, FCC and FCP, respectively are firstly analysed with and without shell imperfections in the compression zone. For the circular tower shape (FCC) a dimple imperfection is applied, as shown in

Figure 11a, with a maximum amplitude of $13 \mathrm{~mm}$ calculated according to EN 1993-1-6 [15] assuming the fabrication tolerance quality class B. For the polygonal tower shape (FCP) a harmonic shape of the local imperfection is applied, as shown in

Figure 11b. The maximum amplitude of the harmonic imperfection of $4 \mathrm{~mm}$ is assumed as approximately $b / 200$, where $b$ is the width of the flat part of the polygonal cross section between two folds. The position of the imperfection is obtained from non-linear analysis of the initially ideal geometry, see Figure 15. This initial deformation is introduced in the subsequent model under a stress-free conditions. 


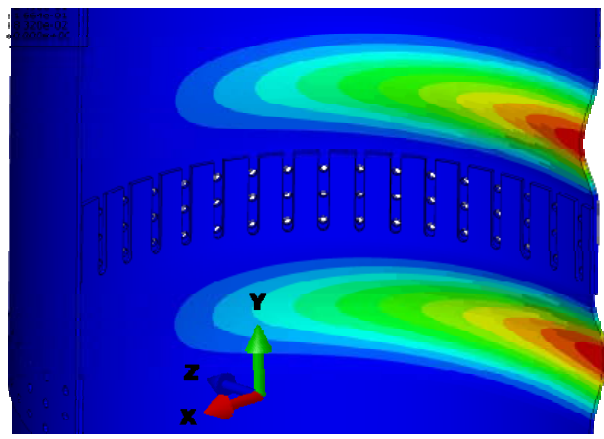

a) circular cross section (FCC)

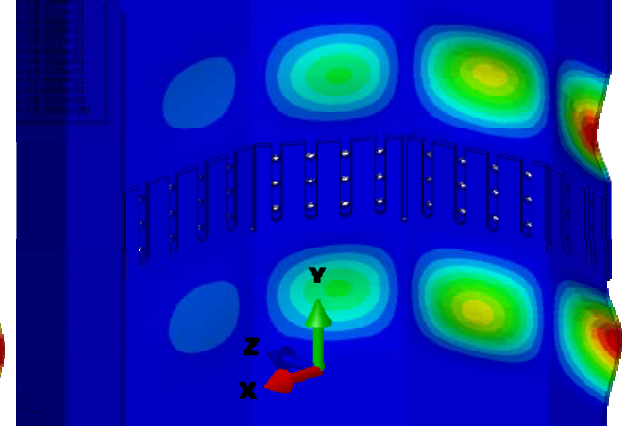

b) polygonal cross section (FCP)

Figure 11. The Imperfections Applied to the Shell, Adjacent to the Connection

\subsection{Execution Tolerances}

A parametric study of the friction connection's bending resistance regarding the execution tolerances is made analysing several parameters: tower shape, length of the connection (length of the "finger"), and type and size of execution tolerance. Two different types of execution tolerances are considered for the friction connection in circular tower: a gap between the shells due to different diameters of the segments and an inclined gap due to bending of fingers, as it is shown in Figure 12. Both alternatives are investigated for the maximum gap in the range of $10-30 \mathrm{~mm}$.
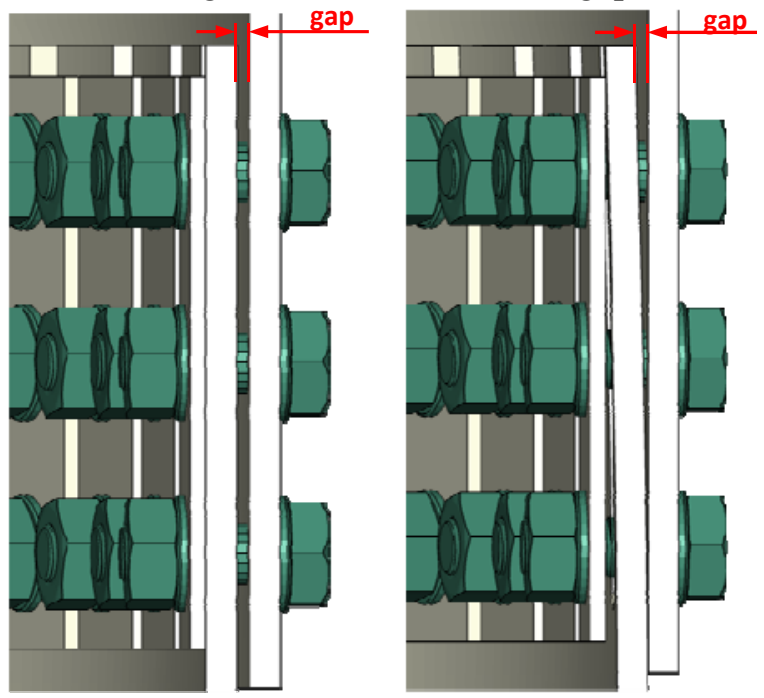

a) parallel gap between the shells b) inclined gap due to bending of the fingers Figure 12. Different Types of the Execution Tolerances.

Denomination of the cases considered in the parametric study is given in Table 3. The first letter indicates the tower shape $(\mathrm{C}$ - circular, $\mathrm{P}$ - polygonal $)$, the second is the digit designating the size of execution tolerance ( 0 means no gap, 1 means $10 \mathrm{~mm}$ gap, 2 means $20 \mathrm{~mm}$ gap, 3 means $30 \mathrm{~mm}$ gap). The third character denotes the steel grade of the shell (B means S460 in this study) and the remaining three digits represent the length of the fingers $\left(L_{\mathrm{F}}=450 \mathrm{~mm}, L_{\mathrm{F}}=550 \mathrm{~mm}\right.$ and $L_{\mathrm{F}}=650 \mathrm{~mm}$ ). The last lower case character defines the type of the execution tolerance $(\mathrm{g}-\mathrm{gap}$ between the shells, $\mathrm{b}$ - inclined gap due to bending of the fingers). The overlapping length in the connection is $50 \mathrm{~mm}$ longer than the fingers in all cases, as shown in Figure 3. Reference cases, with ideal geometry (C0B450 and P0B450), have no gaps between the outer and the inner shell. No dimple imperfections of the shell are taken into account in the parametric study to isolate the problem of stress concentrations and buckling within the connection. 
Table 3. Cases Considered in the Parametric Study

\begin{tabular}{lllll}
\hline Case & $\begin{array}{l}\text { Tower } \\
\text { shape }\end{array}$ & $\begin{array}{l}\text { Execution } \\
\text { tolerance } \\
g(\mathrm{~mm})\end{array}$ & $\begin{array}{l}\text { Length of the } \\
\text { fingers }(\mathrm{mm}) \\
L_{\mathrm{F}}(\mathrm{mm})\end{array}$ & $\begin{array}{l}\text { Type of } \\
\text { exec. tol. }\end{array}$ \\
\hline C0B450 & circular & 0 & 450 & none \\
C1B450g & & 10 & 450 & gap \\
C1B550g & 10 & 550 & gap \\
C1B650g & 10 & 650 & gap \\
C2B450g & 20 & 450 & gap \\
C3B450g & 30 & 450 & gap \\
C1B450b & 10 & 450 & bending \\
C2B450b & 20 & 450 & bending \\
C3B450b & 30 & 450 & bending \\
\hline P0B450 & polygonal & 0 & 450 & none \\
P1B450g & 10 & 450 & gap \\
P1B450b & 10 & 450 & bending \\
\hline
\end{tabular}

In the polygonal tower with assumed execution tolerances, slots are cut at the corners in the connection zone, as shown in Figure 13, to allow the unrestrained deformation of the fingers during preloading of the bolts. For the sake of simplicity no rounded root of the slot in the fold is modelled. The width of those slots is $24 \mathrm{~mm}$ and the length is $50 \mathrm{~mm}$ longer then the fingers. No slots are made in the initial case with perfect geometry where no gap between the shells exists, P0B450.

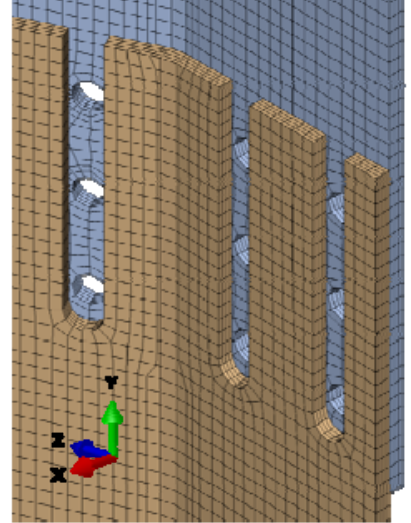

a) P0B450

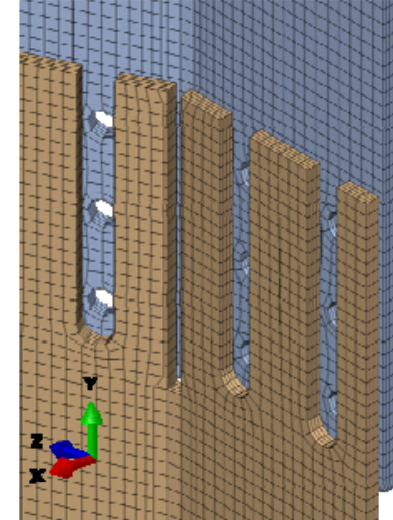

b) P1B450g and P1B450b

Figure 13. Slots at the Corners in the Connection Zone of Polygonal Tower

\section{RESULTS AND DISCUSSION}

\subsection{Number of Folds}

According to the criteria for cross section classification given in EN 1993-1-1 [10], the number of edges (folds) in the tower with polygonal cross section is supposed to be $n_{\text {edge }} \leq 14.7$ to comply with the requirement for cross section class 4 . The slenderness limit, Eq. 1, for the flat segments of the tower assumes that the folds have enough small angle, Eq. 3. For the tower considered here the angel between flat segments of $154^{0}$ corresponds to the $n_{\text {edge }}=14$ according to eq. 3 . is too large to keep folds fixed. This is obvious from results of experiments performed by Tran [16]. Therefore the number is not supposed to be enough to to prevent its displacement at the ultimate limit state governed by the stability. 
$\alpha=\frac{\pi}{2}\left(1-\frac{2}{n_{\text {edge }}}\right) \quad$ for $n_{\text {edge }} \geq 3$

This expectations is confirmed by the analysis performed. It is clearly shown in Figure 14 that the cross section undergoes global buckling characterized by the dominant radial movement of the folds. Larger number of folds will lead to the weaker folds and smaller number of folds will lead to slender segments, however the optimization of polygonal towers are left out of the scope of this paper.

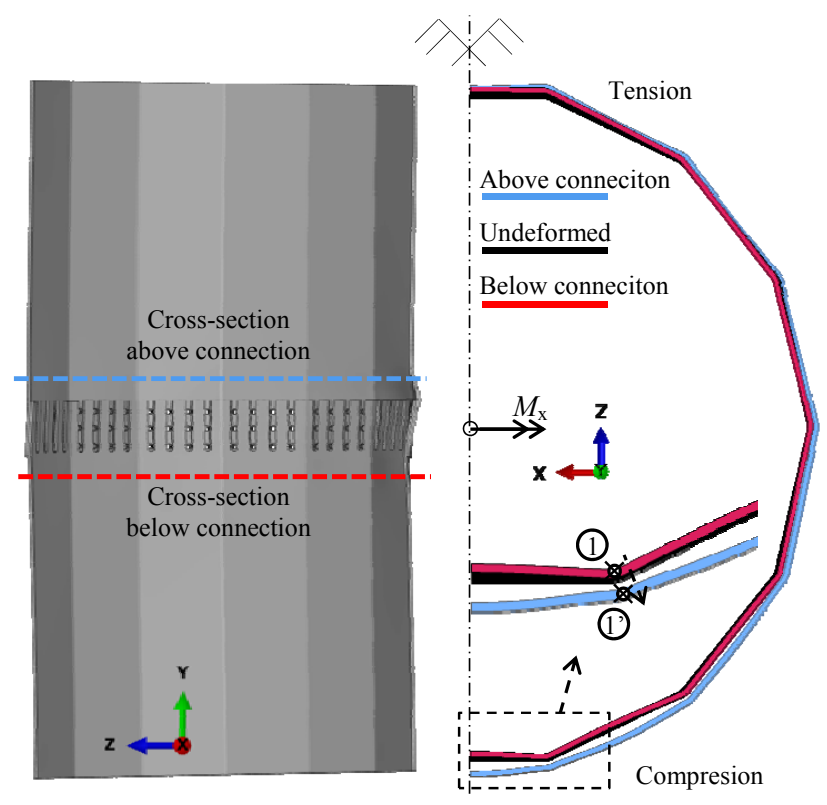

Figure 14. Buckling of the Polygonal Cross Section

\subsection{Influence of the Shell Imperfections}

Post-failure deformed shapes for both cross section cases obtained in FEA without initial dimple imperfections for finger length $L_{F}=450 \mathrm{~mm}$ are shown in Figure 15. Failure mode in both cases is local buckling of the shell, which includes rotation of the whole connection. This appears due to eccentricity of the single lap joint.

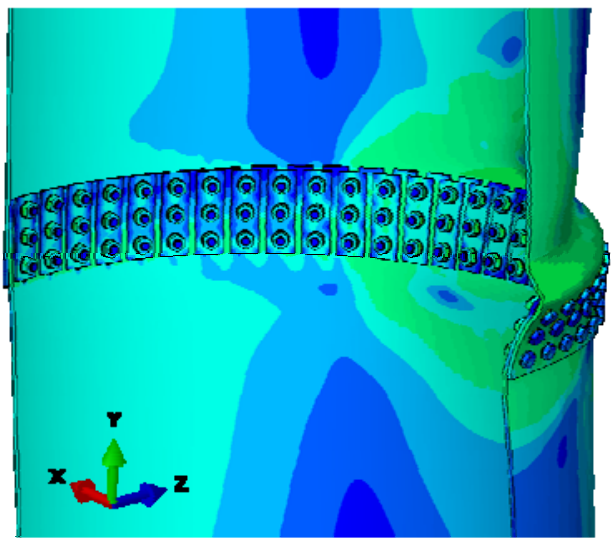

a) $\mathrm{FCC}$

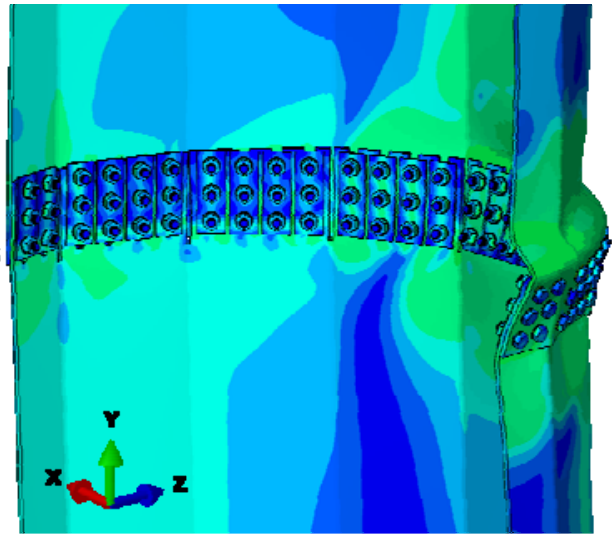

b) $\mathrm{FCP}$

Figure 15. Post-buckling Deformed Shapes for Connections without Shell Imperfections 
Moment-rotation curves for FCC and FCP, with and without imperfections are shown in Figure 16. Initial stiffnesses are identical while the bending resistances are different. In both cases the ultimate buckling resistance $M_{\mathrm{b}, \mathrm{Ru}}$ calculated according to EN 1993-1-6 [15], assuming fabrication tolerance class B, is surpassed.

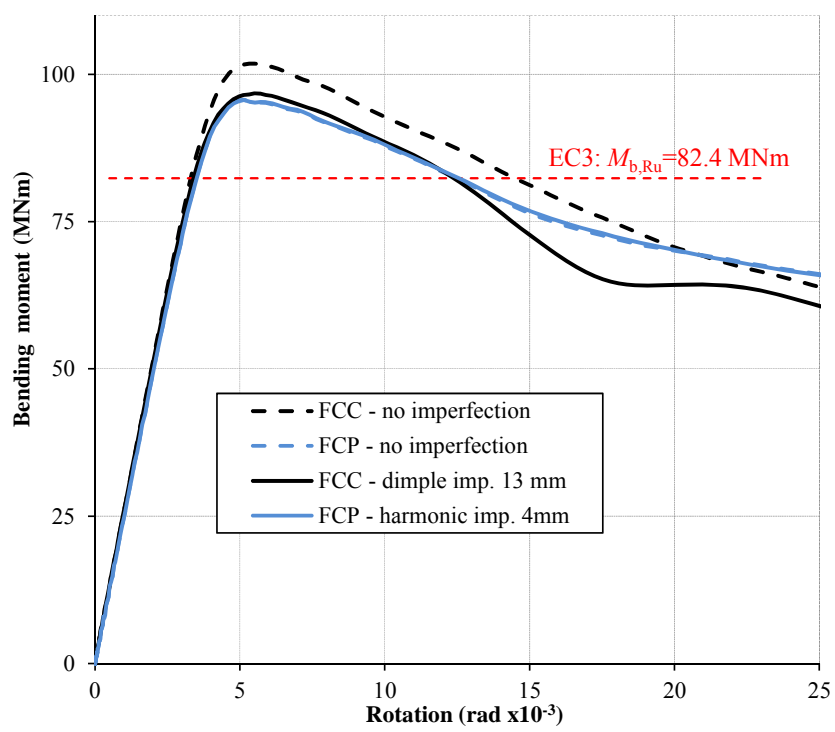

Figure 16. Moment-rotation Curves of FCC and FCP for Finger Length $L_{\mathrm{F}}=450 \mathrm{~mm}$

The bending resistance of the connection in the circular tower without imperfections is $5 \%$ higher compared to the polygonal tower. However, the same ultimate bending moment is obtained in the friction connection in circular and polygonal tower: $96.8 \mathrm{MNm}$ and $95.6 \mathrm{MNm}$, respectively, if imperfections are considered. This is expected as the harmonic imperfections introduced in the polygonal tower are smaller than the dimple imperfections introduced in the circular tower, $5 \mathrm{~mm}$ vs. $13 \mathrm{~mm}$, respectively. The folds in the polygonal tower stiffen the cross section.

Table 4. Bending Resistances of FCC and FCP With and Without Design Shell Imperfections

\begin{tabular}{|c|c|c|c|c|c|}
\hline \multirow[t]{2}{*}{ Case } & \multicolumn{2}{|c|}{ Imperfections } & \multicolumn{3}{|c|}{ Bending resistance (MNm) } \\
\hline & Shape & $\begin{array}{l}\text { Size } \\
(\mathrm{mm})\end{array}$ & $\begin{array}{l}\text { Without } \\
\text { imperfections }\end{array}$ & $\begin{array}{l}\text { With } \\
\text { imperfection }\end{array}$ & $\begin{array}{l}\text { Influence of } \\
\text { imperfection }\end{array}$ \\
\hline $\mathrm{FCC}$ & Dimple & 13 & 101.8 & 96.8 & $-5 \%$ \\
\hline FCP & Harmonic & 4 & 95.7 & 95.6 & $0 \%$ \\
\hline
\end{tabular}

Deformed shapes and meridional stresses in the compression zone of the shell at the load step prior to buckling are shown in Figure 17 for FCC and FCP with design imperfections. Buckling shape in FCC is different compared to the case without imperfection. If imperfections are not considered, the shell local buckling is affected by eccentricity of the single lap joint resulting in an inclination of the whole connection, see Figure 15a. If the design imperfections are applied, buckling occurs in the zone of imperfection without inclination of the whole connection, see Figure 17a. In FCP shell imperfections are rather small, and similar buckling shape including the inclination of the connection can be seen in Figure 15b and Figure 17b. From the influence of design imperfections on the resistance it is clear that the circular tower is more sensitive to buckling of the shell, in the vicinity of the friction connection, compared to the polygonal towers. 


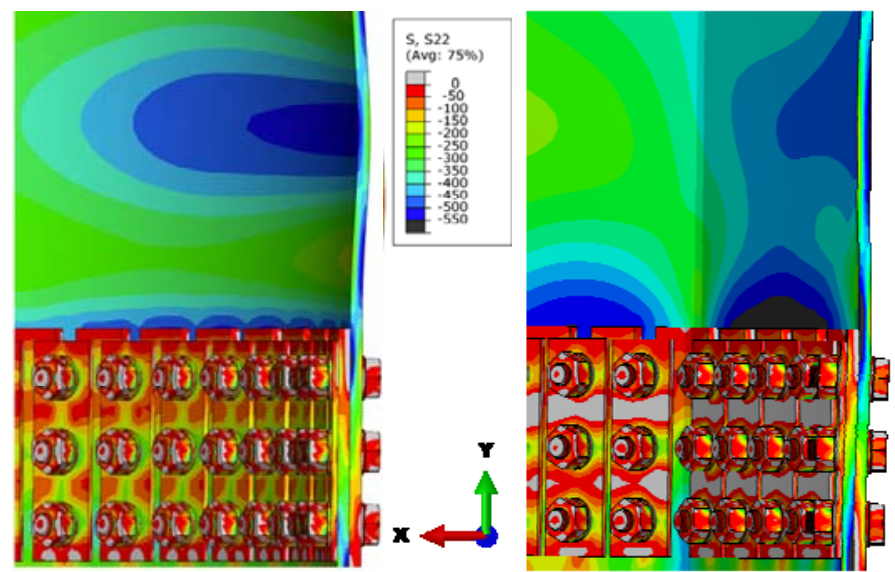

$\begin{array}{ll}\text { a) FCC }(M=90.7 \mathrm{MNm}) & \text { b) FCP }(M=89.5 \mathrm{MNm})\end{array}$

Figure 17. Deformed Shapes and Meridional Stresses in the Shell Prior to Buckling

\subsection{Influence of the Connection Length}

Meridional stresses due to bending of the fingers by preloading of the bolts for different lengths of the fingers are shown in Figure 18. It can be noticed that the case with shortest fingers (C1B450) has the lowest meridional stresses since the gap is closed by the simultaneous deformation of upper and lower shell. In the other two cases (C1B550 and C1B650) closure of the gap between the shells is obtained by bending of the fingers, resulting in larger meridional stresses. Therefore, there is no use of providing long fingers in order to reduce normal stresses in fingers. Certainly, a bit longer slotted holes may be beneficial for alignment of the tower segments during the execution, but this aspect is not taken into account here but there are no structural reasons to use longer fingers, especially not if the inclined gap is obtained in inward bending of the fingers

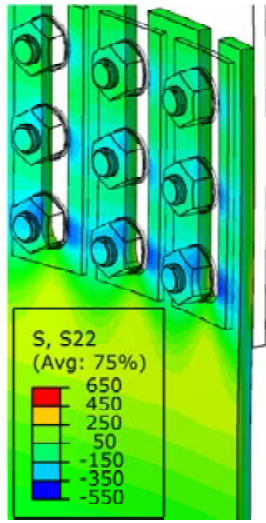

a) C1B450g

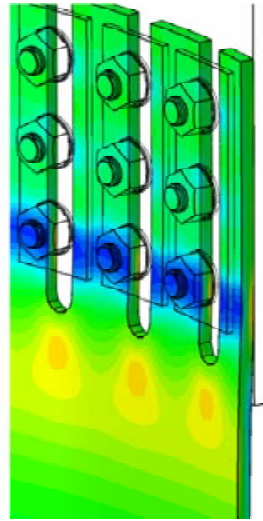

b) C1B550g

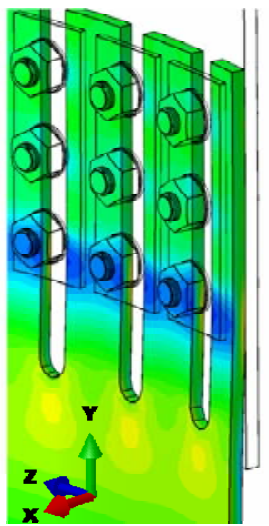

c) C1B650g

Figure 18. Meridional Stresses in the Fingers due to Closing of the Gap by Tightening of the Bolts

\subsection{Influence of the tower shape}

Moment-rotation curves for the friction connection with and without the gap of $10 \mathrm{~mm}$ in both circular and polygonal tower are shown in Figure 19. Reduction of the bending resistance due to execution tolerance is $2 \%$ and $7 \%$, in circular and polygonal tower, respectively, compared to the cases without execution tolerances, see Figure 19 and

Table 5. The larger reduction in the polygonal tower is caused by the reduction of cross section area of the shell by applying the corner slots, see Figure 13. The plastic bending moment resistance of the cross section of the polygonal shell with corner slots $M_{\mathrm{p}, \mathrm{Ru}, \mathrm{red}}=116 \mathrm{MNm}$ is $4.2 \%$ lower than 
the plastic bending moment resistance of the gross cross section $\mathrm{M}_{\mathrm{p}, \mathrm{Ru}}=121 \mathrm{MNm}$. This justifies the difference in reduction of bending moment resistance obtained for the polygonal and circular cross section.

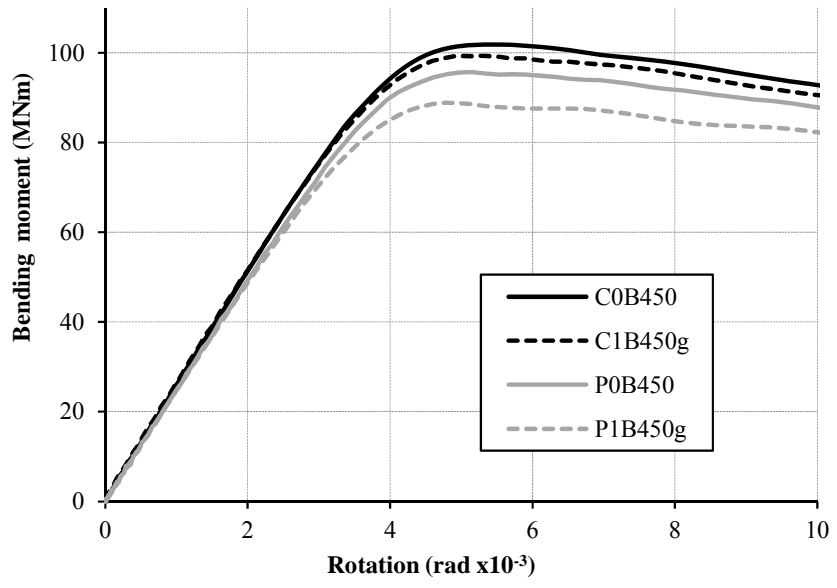

Figure 19. Influence of the Corner Slots in Polygonal Tower on Reduction of Bending Resistance

Table 5. Influence of the Tower Shape

\begin{tabular}{lllll}
\hline Case & $\begin{array}{l}\text { Tower } \\
\text { shape }\end{array}$ & $\begin{array}{l}\text { Execution } \\
\text { tolerance }\end{array}$ & $\begin{array}{l}\text { Ultimate } \\
\text { bending } \\
\text { moment } \\
M_{\text {ult }}(\mathrm{MNm})\end{array}$ & $\begin{array}{l}\text { Reduction } \\
\text { factor }\end{array}$ \\
$M_{\text {ult }} / M_{\text {ref }}$ \\
\hline C0B450 & circular & 0 & $101.8\left(M_{\text {ref }}\right)$ & 1.00 \\
C1B450g & & 10 & 99.3 & 0.98 \\
\hline P0B450 & polygonal & 0 & $95.7\left(M_{\text {ref }}\right)$ & 1.00 \\
P1B450g & & 10 & 88.9 & 0.93 \\
\hline
\end{tabular}

Stress concentrations at the roots of the corner slots in the polygonal tower are caused by preloading of the bolts, see Figure 20b, which can reduce fatigue endurance of the shell. This needs to be assessed in more detail to justify the application of polygonal tower shapes in towers for wind converters (not scope of this study).

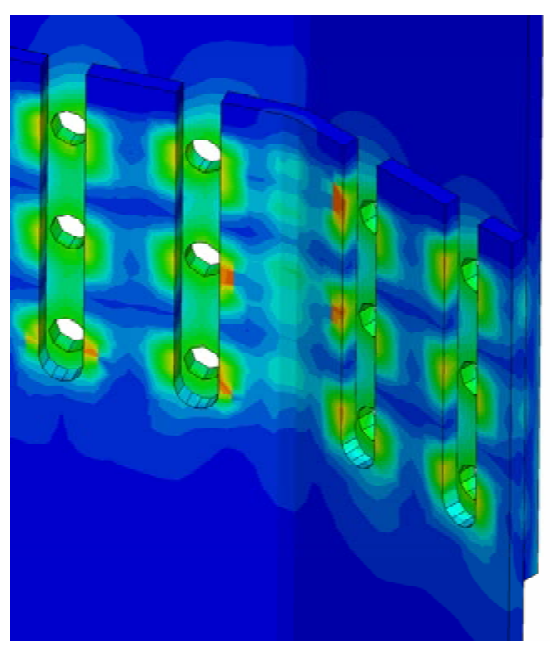

a) P0B450

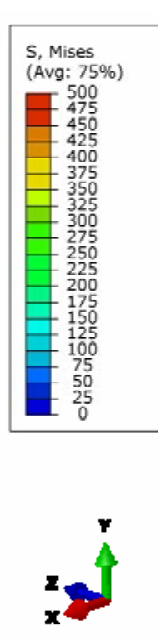

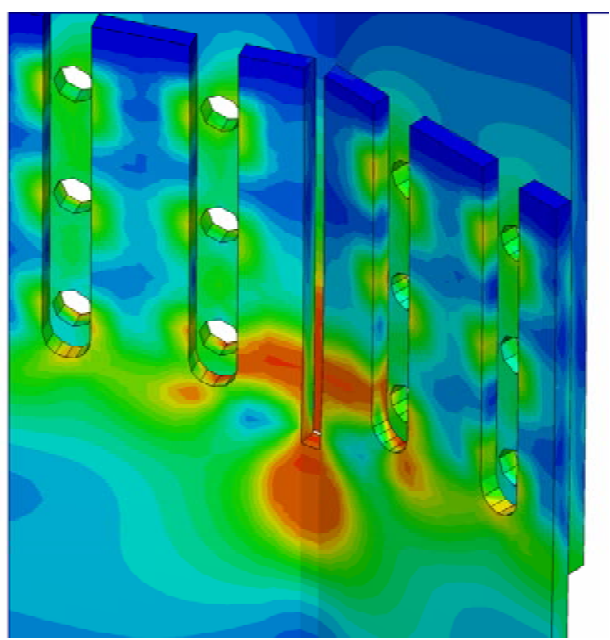

b) P1B450g

Figure 20. Stress Concentration in the Corner Slot of the Polygonal Tower 


\subsection{Influence of the Type and Size of the Execution Tolerances}

Two different methods to provide execution tolerances in the circular tower:

- the gap between the shells, parallel gap established by different diameters of two tower segments with and without fingers

- the same diameter of both tower segments but the inclined gap is established by inward plastic bending of the fingers.,

Different sizes: $10 \mathrm{~mm}, 20 \mathrm{~mm}$ and $30 \mathrm{~mm}$ of the maximum gap, are compared to the reference (theoretical) cases of no gap, in Table 6. The reduction of bending resistance with regards to the parameters considered above is shown in Figure 21.

Table 6. Influence of the Type and Size of Execution Tolerance on Bending Resistance

\begin{tabular}{lllll}
\hline Case & $\begin{array}{l}\text { Type of the } \\
\text { execution } \\
\text { tolerance }\end{array}$ & $\begin{array}{l}\text { Size of the } \\
\text { execution } \\
\text { tolerance } \\
g(\mathrm{~mm})\end{array}$ & $\begin{array}{l}\text { Ultimate } \\
\text { bending } \\
\text { moment } \\
M_{\text {ult }}(\mathrm{MNm})\end{array}$ & $\begin{array}{l}\text { Reduction } \\
\text { factor }\end{array}$ \\
$M_{\text {ult }} / M_{\text {ref }}$ \\
\hline C0B450 & none & 0 & $101.8\left(M_{\text {ref })}\right.$ & 1.000 \\
\hline C1B450g & gap & 10 & 99.3 & 0.975 \\
C2B450g & & 20 & 96.7 & 0.950 \\
C3B450g & & 30 & 94.4 & 0.927 \\
\hline C1B450b & Bending & 10 & 101.2 & 0.993 \\
C2B450b & (inclined) & 20 & 100.2 & 0.984 \\
C3B450b & & 30 & 100.3 & 0.985 \\
\hline
\end{tabular}

The effect of execution tolerance provided by the parallel gap between the shells leads to higher reduction of ultimate bending resistance compared to the inclined gap obtained by the inward bending of the fingers. Almost linear dependency of the reduction factor with regards to the size of the gap between the shells is obtained. With the largest execution tolerance of $30 \mathrm{~mm}$ gap between the shells $7 \%$ reduction of the bending resistance is obtained. Inward bending of the fingers causes very small reduction, which is practically negligible. These results are expected as the less eccentricity is introduced in the tower segment at the connection, if the gap is made by inward bending of the fingers. This is illustrated in

Figure 22, where deformed shapes and meridional stresses after preloading of the bolts and after the failure are shown for the reference case and the two types of execution tolerances.

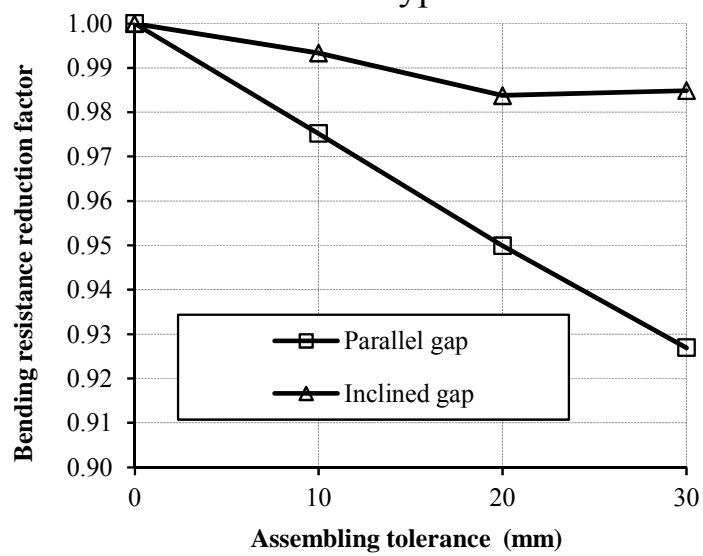

Figure 21. Influence of Execution Tolerances on Bending Resistance of the Connection 


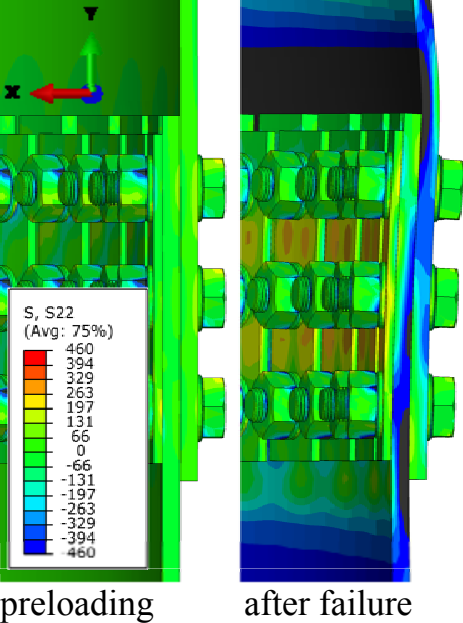

a) no execution tolerance $\mathrm{C} 0 \mathrm{~B} 450$

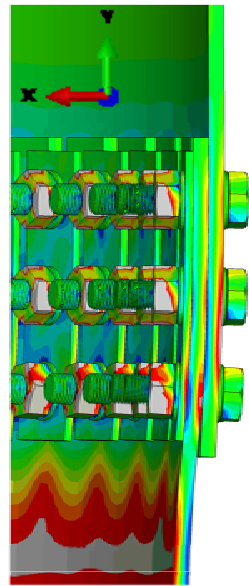

preloading

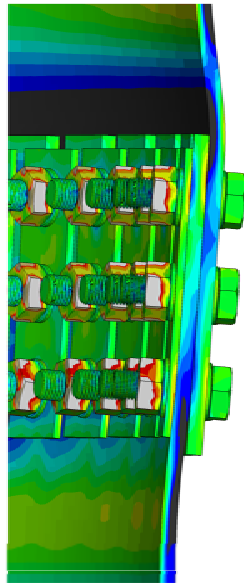

after failure

b) gap between the shells - C3B450g

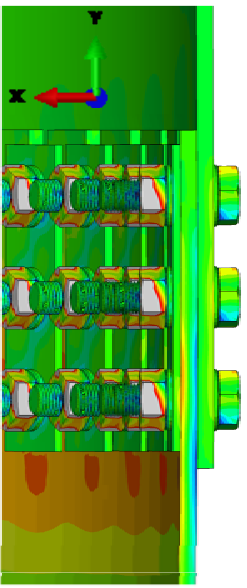

preloading

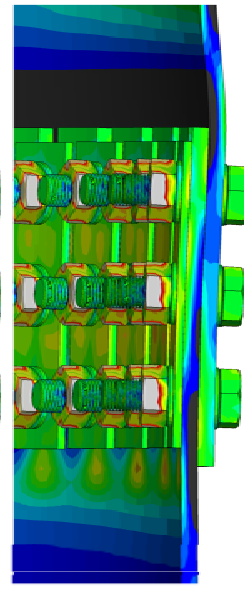

after failure

Figure 22. Deformed Shapes and Meridional Stresses after Preloading of Bolts and after Failure

Meridional stresses along the inner and outer edge of the fingers in the lower shell are shown in Figure 23 for different sizes and types of execution tolerances. Yielding criterion, $f_{\mathrm{y}}=460 \mathrm{MPa}$, is reached below the fingers at $z \approx 650 \mathrm{~mm}$ for the $30 \mathrm{~mm}$ parallel gap, see Figure 23a. The inclined gap is favourable since the meridional stresses are in elastic range, see Figure 23a. Moreover, preloading of the bolts is simpler if the fingers are pre-bent as they can be fully straightened by tightening of the lowest bolt row. Obviously the method of the inward finger bending for achieving the execution tolerances is advantageous.

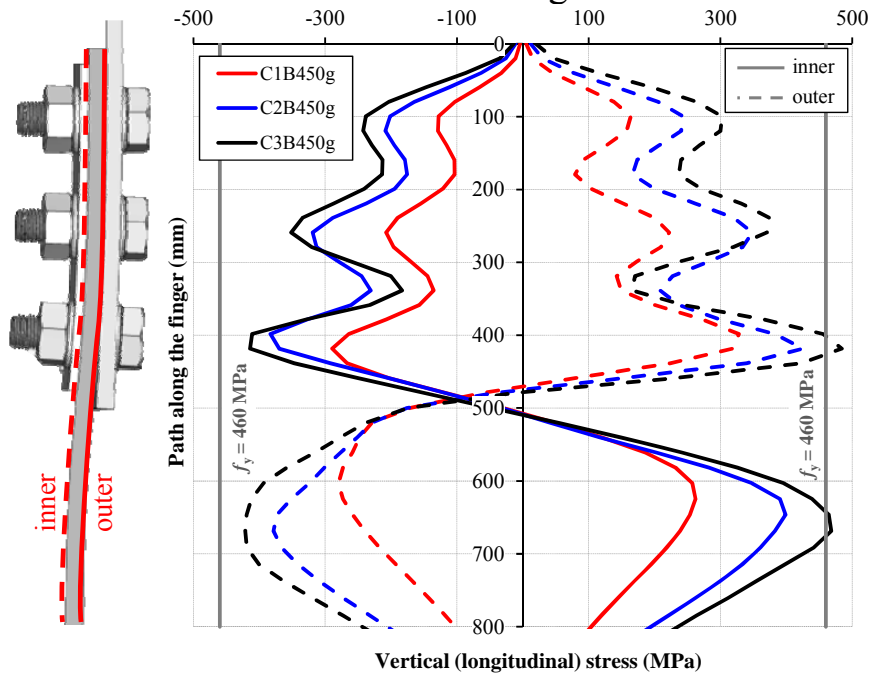

a) parallel gap

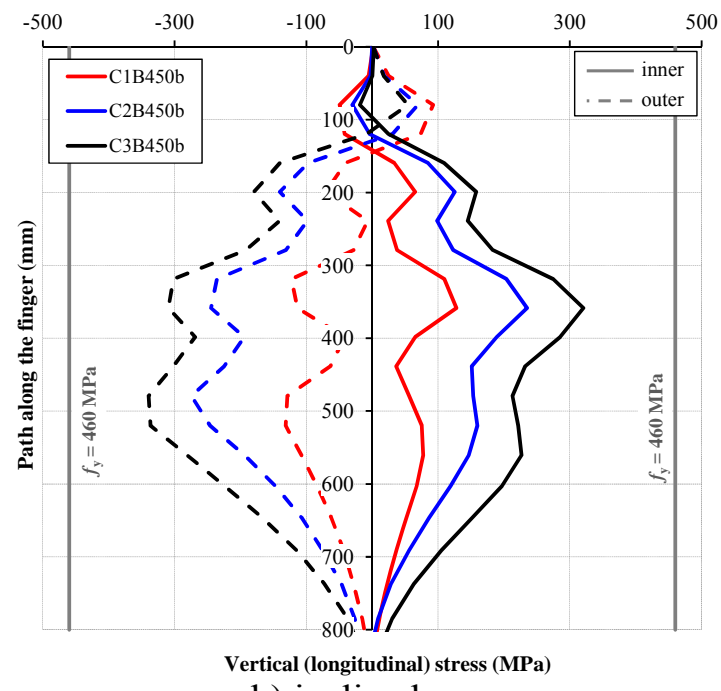

b) inclined gap

Figure 23. Meridional Stresses along the Edges of Inner Shell after Preloading of the Bolts

\section{CONCLUSIONS}

Advanced FEA of the real-scale friction connection in a steel tubular tower for wind energy converter have been conducted, relaying on a FEA verified by down-scaled experiments. The friction connection is analysed in a parametric study considering circular and polygonal tower shape, design shell imperfection, length of the fingers, and size and type of execution tolerance. The following conclusions are drawn: 
1. Provision of the execution tolerance by a parallel gap between the shells higher than $20 \mathrm{~mm}$ produces yielding in the root of the fingers. The bending resistance of the connection is $7 \%$ reduced for an execution tolerance of $30 \mathrm{~mm}$ gap. This method is not recommended for larger execution tolerances. Execution tolerance provided by inward bending of the fingers is recommended. In this case, the inclined gap, practically no reduction of bending resistance is obtained up to a maximum tolerance of $30 \mathrm{~mm}$.

2. The polygonal cross section of the tower is fully effective and no local buckling of the flat part occurs if the number of edges is chosen such that the flat part of the cross section satisfies the slenderness limit for the class 3 cross section according to EN 1993-1-1 [10].

3. Approximately $5 \%$ higher bending resistance of the friction connection is obtained in the circular tower compared to the polygonal tower, if shell imperfections are not considered. However, design imperfections in the polygonal tower are lower compared to imperfections of the circular tower. The same design bending resistance is obtained as for the circular tower.

4. There is no need to use slotted holes that are significantly longer than the group of bolts in the connection since the initial gap between the shells is closed by simultaneous deformations of the upper and lower shell. A small extension of the slotted hole beyond the last bolt in a row ( $1 d_{0}$ is used in this study) should be provided to allow easy alignment of the tower segments during execution.

\section{ACKNOWLEDGEMENTS}

The authors gratefully acknowledge the financial support by the European Research Fund of Coal \& Steel, Grant-Agreements No. RFSR-CT-2010-00031 "High steel tubular towers for wind turbines (HISTWIN2)" as well as the Centrum for High-performance Steel (CHS) at Luleå University of Technology, Sweden and Portuguese Regional Operational Programme CENTRO2020 within the scope of the project CENTRO-01-0145-FEDER-000006.

\section{REFERENCES}

[1] Veljkovic, M., Heistermann, C., Husson, W., Limam, M., Feldmann, M., Naumes, J., Pak, D., Faber, T., Klose, M., Fruhner, K.U., Krutschinna, L., Baniotopoulos, C.C., Lavassas, I., Pontes, A., Ribeiro, E., Hadden, M., Sousa, R., Simões da Silva, L., Rebelo, C., Simões, R., Henriques, J., Matos, R., Nuutinen, J. and Kinnunen, H., "High-strength Tower in Steel for Wind Turbines (HISTWIN)", Final Report - RFSR-CT-2006-00031, 2012, European Commission (RFCS).

[2] Veljkovic, M., Heistermann, C., Tran, A.T., Feldmann, M., Möller, F., Richter, C., Baniotopoulos, C.C., Gerasimidis, S., Zygomalas, I., Matos Silva, A., Simões da Silva L., Rebelo, C., Pinto, P., Matos, R., Moura, A., Gervasio, H., Siltanen, J., "High Steel Tubular Towers for Wind RTurbines (HISTWIN2)", Final Report - RFSR-CT-2010-00031, 2015, European Commission (RFCS).

[3] Pavlovic, M., Heistermann, C., Veljkovic, M., Pak, D., Feldmann, M., Rebelo, C. and Simões da Silva, L., "Connections in Towers for Wind Converters - Part 2: The Friction Connection Behaviour", Journal of Constructional Steel Research, 2015, Vol. 115, pp. 458-466.

[4] Pavlovic, M., Heistermann, C., Veljkovic, M., Pak, D., Feldmann, M., Rebelo, C., Simões da Silva, L., "Friction Connection vs. Ring Flange Connection in Steel Towers for Wind Converters", Engineering Structures, 2015, Vol. 98, pp. 151-162. 
[5] Heistermann, C., Veljkovic M., Simões R., Rebelo, C. and Simões da Silva, L., "Design of Slip Resistant Lap Joints with Long Open Slotted Holes”, J. Constr. Steel Res. 2013, Vol. 82, pp. 223-233.

[6] Garzon, O., "Resistance of Polygonal Cross Sections - Application on Steel Towers for Wind Turbines", Licentiate Thesis, Luleå University of Technology, 2013.

[7] Reinke, T., "Tragverhalten von Stahlmasten mit polygonalem Querschnitt", DASt Kolloqium, Aachen, 2012.

[8] ABAQUS User Manual. Version 6.12. Providence, RI, USA: DS SIMULIA Corp; 2012.

[9] Pak, D. and Naumes, J., "High-strength Tower in Steel for Wind Turbines (HISTWIN): WP2.5 - Large Scale 4-Point-Bending Tests", Background Document RFSR-CT-2006-00031, Brussels, Belgium: European Commission (RFCS), 2010.

[10] EN 1993-1-1, "Eurocode 3: Design of Steel Structures, Part 1-1: General Rules and Rules for Buildings", Brussels, Belgium: European Committee for Standardization (CEN), 2005.

[11] ECCS Publication No. 38, "European Recommendations for Bolted Connections in Structural Steelwork", Brussels, Belgium, ECCS, 1985.

[12] EN 1993-1-8: "Eurocode 3: Design of Steel Structures. Part 1-8: Design of Joints", Brussels, Belgium: European Committee for Standardization (CEN), 2005.

[133] Pavlovic, M., Heistermann, C., Veljkovic, M., Pak, D., Feldmann, M., Rebelo, C. and Simões da Silva, L., "Connections in Towers for Wind Converters - Part 1: Evaluation of Down-scaled Experiments”, Journal of Constructional Steel Research, 2015, Vol. 115, pp. 445-457.

[14] ISO 898-1: "Mechanical Properties of Fasteners Made of Carbon Steel and Alloy Steel. Part 1: Bolts, Screws and Studs", Fourth Edition, Brussels, Belgium: European Committee for Standardization (CEN), 2009.

[145] Pavlović, M., Marković, Z., Veljković, M. and Buđevac, D., "Bolted Shear Connectors vs. Headed Studs Behaviour in Push-out Tests”, J. Constr. Steel Res. 2013, Vol. 88, pp. 134-149.

[15] EN 1993-1-6: "Eurocode 3: Design of Steel Structures. Part 1-6: Strength and Stability of Shell Structures", European Committee for Standardization (CEN), 2007.

[16] Tran, A.T., Veljkovic, R., Rebelo, C. and Simões da Silva, L., "Resistance of Cold-formed High Strength Steel Circular and Polygonal Sections - Part 1: Experimental Investigations", Journal of Constructional Steel Research, 2016, Vol. 125, pp. 227-238. 